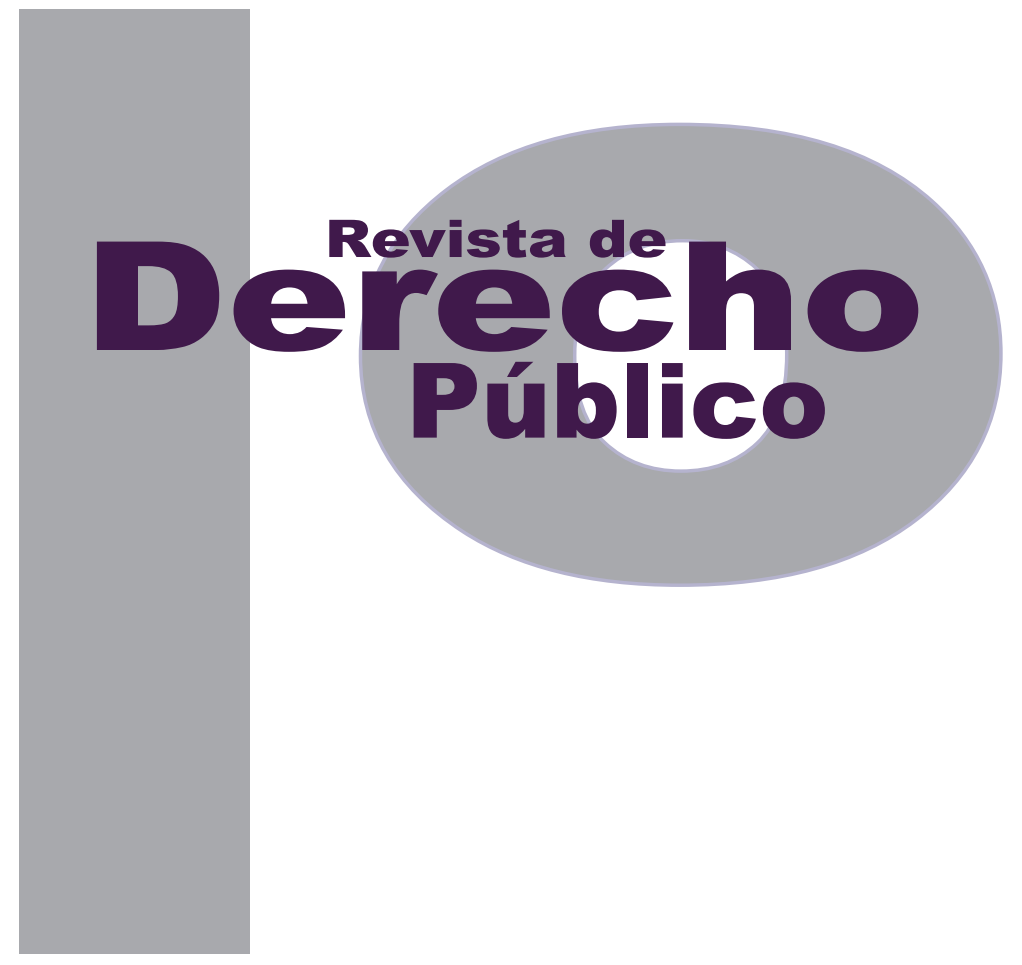

\title{
EL HECHO DEL SECUESTRO POR ACTORES NO ESTATALES DEL CONFLICTO ARMADO: LA TOMA DE MITÚ Y EL SECUESTRO DE INGRID BETANCOURT A LA LUZ DE LA RESPONSABILIDAD DEL ESTADO
}

Yusef Abdel Morad PéRez

Universidad de los Andes

Facultad de Derecho

Revista de Derecho Público N. ${ }^{\circ} 29$

Julio - Diciembre de 2012. ISSN 1909-7778 


\title{
El hecho del secuestro por actores no estatales del conflicto armado: la toma de Mitú y el secuestro de Ingrid Betancourt a la luz de la responsabilidad del Estado
}

\author{
Yusef Abdel Morad Pérez*
}

\section{RESUMEN}

El texto tiene como objetivo indagar sobre el régimen de responsabilidad del Estado aplicable a los casos de secuestro, cometidos por actores no estatales del conflicto armado interno colombiano. Se examina la jurisprudencia existente para dilucidar en qué casos se puede considerar al Estado colombiano como responsable, en aplicación de las diversas construcciones teóricas desarrolladas por la jurisprudencia contenciosa. A partir de esto, se ofrece una hipotética solución jurídica a dos casos famosos de secuestro, ampliamente conocidos por la opinión pública.

Palabras clave: Responsabilidad estatal, secuestro, falla del servicio, riesgo excepcional, nexo de causalidad, posición de garante, Consejo de Estado.

\begin{abstract}
The text aims to inquire the State Liability regime applicable to cases of kidnapping by non-state actors in the context of the Colombian armed conflict. Thus, an exploration of the existing case law is developed, explaining on which situations the Colombian State could be liable through the application of the theories constructed by the specialized Administrative Courts. From this, a hypothetical legal solution for two famous cases of kidnapping widely known to the public opinion is provided by the author.
\end{abstract}

KEY WORDS: State liability regime, kidnapping, faute du service, risk enhancement, damages, causation, guarantor.

Abogado con opción en Lengua y Cultura Italiana de la Universidad de los Andes. Actualmente se desempeña como asistente de investigación del Banco Mundial, en el proyecto Diagnóstico para el Plan Especial de Descongestión de la Jurisdicción Contencioso Administrativa. Correo: ya.morad@ gmail.com 


\section{SUMARIO}

Introducción - I. RÉGIMEN APLICABLE - A. Sustento constitucional - B. Definiciones - C. Estudio de casos - 1. Víctima civil - 2. Conscripto- 3. Militar incorporado a filas voluntariamente $-D$. Conclusiones preliminares - II. CASOS A RESOLVER - A. Mitú - 1. Solución - B. Ingrid Betancourt - 1. Solución - III. CONCLUSIÓN - Bibliografía. 
Introducción

Durante los últimos decenios el delito de secuestro ha sido una realidad inexorable en el contexto del conflicto armado colombiano. Su amplia repercusión en la historia reciente del país es innegable y sus efectos han marcado a una generación entera de connacionales que ha visto el continuo crecimiento de este fenómeno, en su inicio como un mecanismo para la obtención de réditos económicos por parte de los grupos delincuenciales, hasta llegar a ser una herramienta política y de guerra (U. de la Sabana, s.f.). Sus víctimas han sido instrumentalizadas como fuente económica o como herramientas de presión política contra el Estado, al costo de ver violados sistemáticamente sus derechos fundamentales y, en especial, su dignidad como personas.

Ahora, si bien el Estado colombiano no es el que ha cometido materialmente los hechos, dado su rol de actor del conflicto es razonable preguntarse cuál ha sido su papel frente a estos y, en consecuencia, qué responsabilidad podría tener. Y es en el marco de esta pregunta donde la institución de la responsabilidad patrimonial del Estado sirve de instrumento para reflexionar sobre este aspecto de la administración, así como herramienta para restituir algo de lo perdido a las víctimas de este delito.

En este contexto, varios exsecuestrados y sus familiares han manifestado su intención de demandar al Estado para obtener el resarcimiento de los perjuicios por su secuestro. Entre ellos se destacan Ingrid Betancourt (América Economía, 2010), el exdiputado Sigifredo López (El Especta- dor. [EL], Ex diputado..., 2012) -hoy cuestionado por su supuesta intervención en el secuestro de sus compañeros-, así como la viuda del Mayor Guevara (EL, Viuda del..., 16 abril 2012), entre otros. Sin embargo, algunos han desistido a raíz de la polémica causada en la opinión pública, la que incluso les ha tildado de "traidores" al Estado (País Libre, s.f.). De esta forma, la discusión sobre la posible responsabilidad del Estado se ha mantenido en un nivel extrajurídico y no se ha dado el debate sobre cómo reaccionaría nuestro ordenamiento ante tales demandas ni si en realidad la administración tendría responsabilidad.

Ante este panorama, el texto buscará indagar sobre cómo trataría y resolvería nuestro ordenamiento jurídico, a través del instituto de la responsabilidad patrimonial del Estado, los casos en que se endilgue responsabilidad a la administración por los secuestros cometidos por terceros $^{1}$ actores del conflicto armado interno. Para lo cual, resulta fundamental acudir a la jurisprudencia del Consejo de Estado, máximo órgano de la jurisdicción contencioso administrativa, en busca de resolver las siguientes preguntas: a) ¿qué títulos de imputación permiten atribuir responsabilidad al Estado por estos secuestros?; b) ¿cómo se trata el nexo de causalidad cuando el hecho ha sido cometido materialmente por un tercero ajeno al Estado?; y c) ¿qué causales de exoneración permiten excluir la responsabilidad del Estado en estos hechos?

El texto se ha organizado en dos partes: la primera buscará dilucidar el régimen de responsa-

Terceros en el marco de la relación entre la víctima y el Estado, es decir, actores no estatales del conflicto. 
bilidad aplicable a los casos de secuestro, acudiendo a un estudio de casos sobre la jurisprudencia reciente de la Sección Tercera del Consejo de Estado ${ }^{2}$, en particular la proferida entre los años 2009 a 2011. Previo a su exposición, se definirá una serie de conceptos necesarios para el entendimiento del problema. En la segunda parte se realizará un ejercicio práctico, consistente en ofrecer una solución a dos casos de secuestro reales: el de policías, durante la toma de Mitú en 1998, y el de la excandidata presidencial Ingrid Betancourt. Estos casos se reconstruirán a partir de notas de prensa, estableciendo una serie de hechos relevantes sobre los que se aplicarán las conclusiones del primer capítulo del texto.

A través de estas dos herramientas se responderá la duda investigativa, en el sentido que, por lo menos en los dos casos a explicar, sí le asistía responsabilidad patrimonial al Estado y, por ende, una obligación de reparación y restablecimiento sobre los daños y perjuicios sufridos por las víctimas del flagelo del secuestro, en los términos que expondré al lector a lo largo de estas páginas.

\section{RÉGIMEN APLICABLE}

Para la construcción de la primera parte de este escrito se investigó y revisó la base de datos de la relatoría del Consejo de Estado, sin que se encontrara decisión alguna sobre casos donde se imputara responsabilidad al Estado colombiano.

2 Según el art. 13 del Acuerdo 58 de 1999, Reglamento del Consejo de Estado, modificado por el art. 1 del Acuerdo 55 de 2003, conoce de los procesos por acción de reparación directa dentro de la competencia de la Corporación.
Una explicación plausible de la falta de pronunciamientos en la materia por parte del contencioso puede deberse al hecho que la mayor parte de los secuestros cometidos por actores del conflicto, se verificaron durante los años 1996 a 2002, periodo donde se presentaron los siguientes: toma de la base de Las Delicias (1996), toma de la base de Miraflores (1998), secuestro del senador Jorge Eduardo Gechem (2002), entre otros. Debe recordarse que muchos secuestrados fueron liberados muchos años después de su captura, lo que haría que las posibles acciones contenciosas se hayan presentado en años cercanos, sin que los Tribunales hayan siquiera fallado en primera instancia. ${ }^{3}$

Teniendo en cuenta lo anterior, resulta útil acudir a las decisiones existentes sobre aquellos eventos en que los daños a reparar tengan como fuente material el accionar de terceros actores del conflicto armado, es decir, la categoría general, sin discriminar el tipo de delito o bien afectado. La aplicación de razonamientos análogos y generales permite resolver los casos que se presentarán en el capítulo II de este escrito.

Esta revisión iniciará con una breve descripción del sustento normativo que soporta el régimen de responsabilidad estatal en Colombia. Luego se abarcarán las definiciones necesarias para el entendimiento del problema, correspondientes

3 Ejemplo de esto resulta ser el auto del 21 de febrero de 2011, exp. 39360, por medio del cual el Consejo de Estado revoca un auto del Tribunal Administrativo del Meta, que rechazó la demanda presentada por los familiares de un soldado conscripto presuntamente secuestrado (su estatus es el de desaparecido) por las FARC en 1998. Mientras el Tribunal consideró que se había presentado el fenómeno de la caducidad por haberse radicado la demanda el 13 de julio de 2010 , el Consejo de Estado expresó que por tratarse de una presunta desaparición forzada, la caducidad debe contarse desde que aparezca la víctima o desde la ejecutoria del fallo definitivo del proceso penal. 
al daño antijurídico ${ }^{4}$, los títulos de imputación, y por último el nexo de causalidad y sus correspondientes teorías. Hecho esto, se expondrá el estudio de casos realizado sobre los pronunciamientos de la Sección Tercera del Consejo de Estado.

\section{A. Sustento constitucional}

El ordenamiento jurídico colombiano tiene su sustento en las disposiciones de la Carta de 1991 (Peña, 2009, p. 7), además de establecer un derrotero ético (Gil, 2010, p. 58-59), basado en el respeto, promoción y protección de la dignidad humana. En virtud de lo anterior, la Carta Política establece una serie de fines esenciales para el Estado, que deben orientar toda actuación de las autoridades públicas. Dentro de estos se destaca lo normado por el inciso segundo del art. 2 de la Constitución, en cuanto a que la razón de ser de las autoridades es la protección de los residentes en el país, respecto a su vida, honra y creencias, así como los demás derechos protegidos por el ordenamiento. Esta obligación general resulta ser el primer sustento de la responsabilidad estatal, tal como ha sido reconocido por el Consejo de Estado (Exp. AG2001-00213, 2006).

Ahora bien, la Carta de 1991 constitucionalizó la responsabilidad estatal a través del artículo 90, que establece: “El Estado responderá patrimonialmente por los daños antijurídicos que le sean imputables, causados por la acción o la

4 Cabe aclarar que en cuanto al daño se expondrá solo su concepto, sin adentrarnos en una discusión exhaustiva que pueda dar cuenta de las diferentes clasificaciones en torno al concepto que se plantea. Para mayor información sobre el tema puede consultarse la referencia Gil (2010). omisión de las autoridades públicas. [...]." La norma reconoce los elementos generales de la responsabilidad estatal, a saber, el daño antijurídico, la imputación (compuesta por el título de imputación y el nexo de causalidad entre este y el daño), y el deber de responder patrimonialmente, además de establecer las modalidades de causación del daño, es decir, por acción u omisión. Es alrededor de estos elementos que la jurisprudencia ha seguido su desarrollo hasta la actualidad, sin que a la fecha haya habido un desarrollo legal de la responsabilidad estatal, salvo contadas excepciones ${ }^{5}$. Este particular hecho hace que la jurisprudencia contencioso administrativa se constituya en la fuente de derecho primordial en la materia ${ }^{6}$, más allá de que, a la luz del artículo 230 de la Constitución, sea considerada como un criterio auxiliar.

\section{B. Definiciones}

Ahora es necesario definir las instituciones que dan forma a la responsabilidad estatal, es decir, el daño antijurídico, los diversos títulos de imputación usados por la jurisprudencia y el nexo de causalidad, a fin de que el lector tenga un referente conceptual que guíe la lectura.

Daño antijurídico: ${ }^{7}$ el daño antijurídico es aquel que una persona sufre, sin que exista una nor-

5 Por ejemplo, la responsabilidad por el error judicial, normada por la Ley 270 de 1996 y la responsabilidad en materia contractual, reglada por el art. 50 de la Ley 80 de 1993.

6 Téngase en cuenta la reforma introducida por las leyes 1395 de 2010 y 1437 de 2011, en cuanto a la obligatoriedad de los precedentes de las altas cortes.

7 Véase Gil (2010, p. 69), Henao (1998, p. 36, 84), Ruiz (2010, p. 52), y las sentencias del Consejo de Estado CE-Exp. 16241, 2007, como se cita en Gil (2010, p. 64) y CE-Exp. 13168, 2006. 
ma jurídica que exija o justifique tal afectación. Por el contrario, el daño es "jurídico" cuando tal justificación u orden sí exista, como por ejemplo, el pago de tributos o sufrir una lesión como resultado de una legítima defensa, así como la limitación de ciertos derechos (excluidos los derechos fundamentales) en vigencia de los estados de excepción constitucionales ${ }^{8}$.

Falla del servicio: $:-9$ la falla del servicio es un título subjetivo que permite la imputación de responsabilidad a la administración cuando el Estado cumple defectuosamente sus obligaciones, lo hace tardíamente o simplemente no lo hace. Se puede dar en la modalidad de acción o de omisión, esto es, cuando la administración omite cumplir un deber legal preestablecido. En este último caso resulta indispensable tener en cuenta la noción de falla relativa del servicio (CE, exp. 5737, 1990), según la cual la administración solo será responsable cuando esta ocurre en un contexto donde la prestación del servicio era posible, sin que las dificultades presupuestales sirvan de justificación a la ineficiencia o ineficacia del Estado. De esta forma, se reprocha la falta de acción por parte del Estado solo frente a un contenido normativo, en tanto no se juzga si realmente su accionar hubiese impedido la causación de daños.

Riesgo excepcional: ${ }^{-10}$ corresponde a otro título de imputación, pero de carácter objetivo, don-

8 Contemplados en los artículos 212, 213 y 215. La Ley 137 de 1994 regula la materia.

9 Véase Bustamante (2003, p. 39), Ruiz (2010, p. 2, 11, 12) y la sentencia CE-Exp. 5737, 1990.

10 Véase Bustamante (2003, p. 84, 85), Ruiz (2010, p. 20) y la sentencia CE-Exp. 19067, 2011. de no interesa, a fin de determinar responsabilidad, la calificación como lícita o ilícita de la conducta estatal, sino la ocurrencia de un daño con características especiales. La responsabilidad se deriva, en este caso, del ejercicio de actividades o la utilización de cosas peligrosas ${ }^{11}$ por parte del Estado ${ }^{12}$. Al realizar tales actividades, el Estado devenga un beneficio a su favor o en el de toda la comunidad, a costa de crear una carga excepcional no soportable sobre los bienes jurídicos de los individuos, que destruye la igualdad ante las cargas públicas e impone el deber de reparación (Bustamante, 2003, p. 85). Por consiguiente, cuando el Estado produce daños con esas actividades o cosas debe entrar a reparar, buscando el restablecimiento del equilibrio roto con la concreción del riesgo previsible por la naturaleza misma de la cosa o actividad, a fin de que el ciudadano afectado no tenga que soportar él solo tales externalidades.

Daño especial: ${ }^{13}$ el tercer título de imputación consiste en el denominado daño especial. Al igual que el riesgo excepcional, es de carácter objetivo, pero a diferencia de este, donde el actuar estatal puede ser lícito o ilícito, el daño especial necesariamente excluye la falla. ${ }^{14}$ En los

11 "Las cosas se consideran peligrosas cuando por su propia estructura y naturaleza son potencialmente dañinas, de tal manera que respecto de ellas lo normal y ordinario es la previsibilidad del daño." (Bustamante, 2003, p. 84).

12 La jurisprudencia ha considerado el riesgo excepcional como título de imputación en los casos de uso de armas de dotación oficial, conducción de vehículos, redes de energía eléctrica y los casos de ataques terroristas contra bienes u objetivos estatales, entre otros. (Ruiz, 2010, p. 20).

13 Véase Bustamante (2003, p. 111), Ruiz (2010, p. 17) y sentencia CE, exp. 10952, 2002.

14 En consecuencia, es un título residual solo aplicable en la ausencia de los otros (CE, exp. 10952, 2002). 
eventos en que un daño se impone a toda la colectividad, no hay nada que reprocharle al Estado, en tanto no se comete injusticia al imponer sacrificios a fin de la procura del bienestar común y el logro de los fines estatales. Por el contrario, si el daño se produce con violación del equilibrio de las cargas públicas, favoreciendo el interés general a costa de la afectación exclusiva de alguna o algunas personas, se configura responsabilidad.

Nexo de causalidad: $\frac{15}{15}$ este elemento es el vínculo necesario que debe existir entre cualquiera de los títulos de responsabilidad y los daños antijurídicos que se le imputan al Estado. Debe tenerse en cuenta que el concepto de causa no es igual en el mundo jurídico que en el mundo de las ciencias exactas, puesto que lo que es una causa material (causa física) no necesariamente lo es jurídicamente. La material se llama imputación fáctica, mientras que la jurídica es la fuente normativa del deber de reparación (CE, exp. 13744, 2002), siendo posible que, en algunas ocasiones, unos hechos sean causa material y otros "causa jurídica".

Ahora bien, existen diversas teorías para explicar el nexo de causalidad. Anteriormente la jurisdicción contenciosa aplicaba la denominada equivalencia de condiciones ${ }^{16} \mathrm{y}$ en la actualidad

15 Véase Tamayo (1996, p. 245-246) y sentencias CE, exp. 13744, 2002 y CE, exp. 19977, 2011.

16 Según Tamayo (1996, p. 245-246), la equivalencia de condiciones entiende que todas las causas (materiales) contribuyen a la ocurrencia del daño desde el punto de vista jurídico y, por ende, se genera el deber de reparación para todos aquellos detrás de estas. Sin embargo, la teoría ha sido desechada, tanto por doctrina, como por jurisprudencia, en tanto produce una regresión al infinito en busca de culpables. la teoría de la causalidad adecuada ${ }^{17}$. Estas, sin embargo, no permiten sustentar las omisiones, en tanto de la nada no surge nada (CE, exp. 19977, 2011). Ante esta situación, la jurisprudencia ha utilizado la noción del derecho penal Ilamada imputación objetiva, entendida como un conjunto de herramientas jurídicas y normativas que permiten solucionar este tipo de problemas causales (CE, exp. 19977, 2011). Entre estas, la teoría de la posición de garante resulta especialmente útil a fin de establecer el nexo entre una omisión y el resultado dañoso que se imputa al Estado. Corresponde a la identificación de las situaciones en las cuales el no impedir un resultado equivale a realizarlo (CE, exp. 19977, 2011), en tanto un deber jurídico compele a la acción.

\section{Estudio de casos}

Explicados los conceptos necesarios, es posible comenzar con el estudio de los casos relevantes. Se utilizará como categoría de análisis la calidad del sujeto que fue objeto del hecho dañoso imputado al Estado, es decir, si la persona asesinada, lesionada o afectada en cualquier forma, era un civil, un militar conscripto (ciudadano-soldado ${ }^{18}$, o un militar que voluntariamente se haya unido al cuerpo castrense. ${ }^{19}$

17 La causalidad adecuada establece que solo los hechos que normalmente han debido producir el daño evaluado son causa jurídica (Tamayo, 1996, p. 245-246).

18 Expresión utilizada por el Consejo de Estado en algunos de los casos analizados.

19 Estas categorías fueron elegidas toda vez que la lectura de los casos a exponer evidenció un disímil tratamiento por parte del Consejo de Estado de los problemas jurídicos y cierta exigencia probatoria diferente, lo que permite su clasificación por grupos y la extracción de conclusiones específicas en cada una de las categorías. 
En cada uno de los casos se revisarán: título de imputación y teoría de causalidad aplicada, y causales de exoneración esgrimidas para la defensa del Estado.

Los casos a analizar corresponden a los siguientes: había atendido el incendio y funcionarios suyos tuvieron conocimiento de las amenazas, a pesar de lo cual no se dispuso un mecanismo de protección a su favor. Por su parte, la Policía alegó, entre otros, el hecho de un tercero como causal de exoneración de responsabilidad.

\begin{tabular}{|c|c|c|c|}
\hline Categoría & Nombre caso ${ }^{20}$ & Número sentencia ${ }^{21}$ & Fecha sentencia \\
\hline \multirow{4}{*}{ Civil } & Subdirector cárcel Florencia & 18106 & 25 de febrero de 2009 \\
\hline & Unión Patriótica - Julio Serrano & 16836 & 1 de abril de 2009 \\
\hline & Candidato Alcaldía de Saravena & 18617 & 26 de enero de 2011 \\
\hline & Alcalde de Jambaló & 20325 & 11 de agosto de 2011 \\
\hline \multirow{2}{*}{$\begin{array}{l}\text { Conscripto (ciu- } \\
\text { dadano-soldado) }\end{array}$} & Toma a Las Delicias & $\begin{array}{l}\text { 15838, 18075, } 25212 \\
\text { (acumulados) }\end{array}$ & 25 de mayo de 2011 \\
\hline & Toma a Las Delicias 2 & 18747 & 25 de mayo de 2011 \\
\hline \multirow{2}{*}{ Militar voluntario } & Estación de Barbacoas & 19195 & 31 de agosto de 2011 \\
\hline & Jefe S2 de Medellín & 17138 & 11 de noviembre de 2011 \\
\hline
\end{tabular}

\section{Víctima civil ${ }^{22}$}

El primer caso a analizar corresponde al exp. 18106, donde los familiares solicitaban la declaración de responsabilidad de la Nación-Policía Nacional, por la muerte de Carlos Arturo Álvarez, quien se desempeñaba como subdirector de la cárcel de Florencia en el año de 1996. El señor Álvarez se encontraba en una especial situación de seguridad, toda vez que días previos a su muerte su casa había sido incendiada. Si bien el señor no hizo una solicitud especial de protección a la Policía, esta entidad sí tenía conocimiento de su situación de seguridad, pues

20 Los nombres fueron seleccionados por el autor a partir de los hechos de cada sentencia.

21 Corresponde al número interno asignado por el Consejo de Estado.

22 Esta categoría de análisis corresponde a los casos en que la víctima no tiene la calidad de militar o policía, es decir, no es parte del conflicto.
Ahora bien, el título de imputación aplicado correspondió a la falla del servicio de protección por omisión. Para llegar a esto, el Consejo de Estado estableció que a la Policía le asiste el deber legal de protección de la población, en virtud del art. 2 de la Constitución y la Ley 62 de 1993, por lo que el no poner todos los medios a su disposición para cumplir con este genera su responsabilidad. Adicionalmente, son tres las situaciones en que se debe entrar a responder, a saber: cuando se deja a la población a merced de los grupos delincuenciales, cuando un ciudadano solicita protección especial y esta no se le presta y cuando a pesar de no existir tal solicitud, el contexto hace evidente a la autoridad la necesidad de prestar protección. En todo caso, la sección no olvida el concepto de relatividad en la falla, pero recuerda a su vez que si bien no se le puede pedir imposibles al Estado, sí se le debe exigir todo lo que esté a su alcance, de- 
biéndose hacer en cada caso una evaluación de las condiciones y el contexto. En consecuencia, considera configurada la falla del servicio.

En cuanto al nexo de causalidad, no es claro qué teoría fue usada, a pesar de que se evidencia un razonamiento similar al de la posición de garante, pudiéndose suponer que la Policía adquirió tal carácter al conocer las amenazas. La misma situación se presenta en cuanto al hecho del tercero, puesto que no se argumenta por qué no excluye la responsabilidad de la entidad. De esta forma, la sentencia resulta condenatoria y a favor de los demandantes.

El segundo caso a analizar corresponde al exp. 16836, sobre la desaparición del señor Julio Serrano, militante de la Unión Patriótica y tesorero municipal de Mesetas, Meta. Los demandantes reclamaban indemnización por parte de la Nación-Ministerio de Defensa-Ejército Nacional, por considerarlas responsables de los perjuicios sufridos. El señor Serrano había sido amenazado ${ }^{23} y$, en consecuencia, se le había hecho entrega de dos armas por parte del municipio, armas que le fueron quitadas por el Ejército cinco meses antes de su desaparición. A pesar del hecho notorio del riesgo que sufría, el Ejército Nacional no le prestó protección alguna.

Aquí, el título de imputación es nuevamente la falla del servicio de protección por omisión, por lo cual se aplican los mismos requisitos que en

23 La sentencia hace especial énfasis en que la condición de la víctima, como miembro de la Unión Patriótica, hacía que el peligro sobre su integridad fuera un hecho notable, dada la persecución masiva, desapariciones y asesinatos de los que fueron objeto los militantes de este partido durante esos años. el caso anterior, así como la salvedad de la falla relativa. Adicionalmente, se tiene como obligación del Ejército el cumplimiento de lo ordenado por el artículo 2 de la Constitución, mediante la puesta en marcha de todos los recursos disponibles a fin de proteger a la persona amenazada. Por tanto, se encuentra configurada la falla.

En cuanto al nexo, se descarta la necesidad de evidenciar una relación causal entre el daño y la omisión, estableciendo que el nexo se encuentra al comprobar que si el Estado hubiese actuado, se hubiese interrumpido el proceso causal material que produjo el daño. Por último, nuevamente no se argumenta por qué se descarta la causal de exoneración del hecho del tercero, condenándose a la entidad a reparar los perjuicios generados.

El tercer caso corresponde a la muerte de un candidato a la alcaldía de Saravena, Arauca, a la finalización de un mitin político. Los demandantes alegaban una falla en el servicio de protección por parte del Ejército y Policía Nacional, toda vez que al momento de la muerte ninguna entidad prestó protección a la víctima. Como hecho relevante se tiene acreditado que existía una especial perturbación del orden público, ante amenazas subversivas por la inminencia de las elecciones políticas del año 1997. Por lo anterior, el Gobierno Nacional había expedido el Decreto 2008 de 1997, buscando la protección de los ciudadanos participantes en el proceso electoral. En este contexto, se había solicitado acompañamiento en seguridad para el mitin donde fue asesinado el candidato, sin que el Ejército hiciese presencia. Por su parte, la Policía se retiró antes de la finalización del evento, 
hecho que aprovecharon los delincuentes para cometer el ilícito.

Al igual que en los casos anteriores, se deriva una obligación de protección a cargo de las Fuerzas Armadas (FFAA), a partir de lo estipulado en el art. 2 de la Carta Política. Sin embargo, se añade el elemento de los derechos humanos, al afirmarse que el Estado tiene una doble obligación frente a estos: tanto el no violarlos directamente, como el impedir su violación por parte de los particulares. Por consiguiente, se considera que las entidades omitieron el cumplimiento de su obligación de protección, al no haber actuado ante un contexto de violencia públicamente conocido, omisión que facilitó la concreción de los daños contra la víctima. Como punto adicional, el Consejo hace especial énfasis en que la situación de una persona con la calidad de candidato, en época de elecciones y en una zona de orden público complicado, genera para la autoridad un deber de protección reforzado.

Este último punto evidencia la aplicación de ciertos elementos de la posición de garante. Si bien no se afirma directamente, se muestra como fundamento que el Estado es el garante de los derechos humanos, garantía que se activa cuando se conoce que puedan estar amenazados, sea por la notoriedad de las amenazas o porque la víctima directamente pone en conocimiento la situación. Nuevamente no hay un análisis especial de la causal de exoneración.

En el cuarto y último caso de la categoría se buscó la declaratoria de responsabilidad de las mismas entidades, ante la muerte del alcalde del municipio de Jambaló, Cauca, fundamentando la reclamación en el mismo tipo de falla. Como hechos relevantes se tiene que la zona de ocurrencia del delito era de difícil orden público, por lo que no existía presencia de las instituciones demandadas. No existió solicitud especial de protección por parte de la víctima.

Como puede verse, se sigue utilizando el mismo tipo de falla, con iguales características y condiciones, pero se flexibiliza mucho más el elemento de la notoriedad de las amenazas contra la víctima y la población en general. Ya no es la simple notoriedad por ser una persona relevante, sino que la misma se extiende a la generalidad de la población de una zona "roja" en materia de orden público, donde era ampliamente conocida la amenaza que generaban los grupos al margen de la ley.

A diferencia de los anteriores casos, directamente se dice que las FFAA tienen una posición de garante de la protección de los derechos humanos (Corte Constitucional, SU-1184, 2001), tanto porque no pueden violarlos, como porque deben evitar la concreción de daños sobre estos por parte de terceros. De esta manera, se introduce de forma completa la teoría de la imputación objetiva, estableciendo como requisito para su configuración la ocurrencia de cualquiera de los siguientes aspectos: “i) con fundamento en el ordenamiento jurídico se tenía el deber de impedir la materialización del daño (posición de garante); ii) con su actividad se incrementó el riesgo permitido [...]; o iii) se estaba dentro del ámbito de protección de una norma de cuidado."

Ahora bien, frente a la posición de garante identifica como generadora de la misma lo siguiente: 
a) Se deja a la población a merced de los grupos de delincuencia, sin brindarles protección alguna, en especial cuando se tiene conocimiento de que los derechos de esa población vienen siendo desconocidos por grupos organizados al margen de la ley; b) se solicita protección especial, con justificación en las especiales condiciones de riesgo en que se encuentra la persona; c) no se solicita expresamente dicha protección pero es evidente que la persona la necesitaba, en consideración a que existían pruebas o indicios conocidos que permitieran asegurar que la persona se encontraba amenazada o expuesta a sufrir graves riesgos contra su vida, en razón de sus funciones.

Esto sin perder de vista la relatividad del servicio, en la que el contexto define las condiciones de exigibilidad de la actuación estatal. Estas mismas consideraciones le permiten despachar la causal de exoneración del hecho del tercero, toda vez que se hace irrelevante que el daño haya sido causado materialmente por este, puesto que lo relevante es que no se haya puesto en marcha el aparato estatal para evitar la concreción de la previsible violación de los derechos humanos de la víctima, a pesar de contar con las herramientas para hacerlo. De esta forma, las entidades fueron condenadas patrimonialmente.

\section{Conscripto}

Esta categoría corresponde a la primera en que la víctima tiene la condición de miembro de las FFAA (Ejército y Policía Nacional) ${ }^{24}$, frente a la cual la jurisprudencia contenciosa ha desarrollado

24 Constitución Política de 1991, art. 216. una línea jurisprudencial particular diferenciada de la aplicada a los civiles, en cuanto a los daños que sufran con ocasión de los hechos ilícitos de grupos delincuenciales y partes del conflicto armado. Adicionalmente, dentro del mismo grupo se ha creado un régimen especial de responsabilidad para los casos en que el militar ha sido vinculado a las FFAA coercitivamente, en cumplimiento del servicio militar obligatorio que incumbe a todos los colombianos.

Para la ejemplificación de lo anterior, se toman como fuente las dos sentencias proferidas en el 2011 respecto a los hechos de la toma de la base militar de Las Delicias, Putumayo, por parte de guerrilleros de las Fuerzas Armadas Revolucionarias de Colombia (FARC), en la cual resultaron muertos, lesionados o secuestrados un elevado número de conscriptos. Tanto la una, como la otra, serán analizadas como una sola, en atención a que los fundamentos jurídicos y análisis realizados por el Consejo de Estado son idénticos, además de tener una misma causa ${ }^{25}$.

Los hechos relevantes de la toma son los siguientes. Los soldados víctimas fueron reclutados para la prestación de su servicio militar en los años 1995 y 1996, y remitidos a la base militar. Esta estaba ubicada en un lugar difícilmente protegible y no contaba con los elementos suficientes para repeler posibles ataques, tanto así que con posterioridad se consideró inútil y fue desmontada. Los ataques eran altamente probables, ante la masiva presencia de subversivos

25 En la primera de las sentencias (Exp. 15538, 18075, 25212), el daño corresponde a la muerte de un soldado conscripto y las lesiones graves de otros dos, mientras que en la segunda (exp. 18747), el daño consiste en las lesiones a un conscripto. 
en sus alrededores. Cuando los soldados fueron remitidos no se les dio la suficiente instrucción, no se les entregaron armas ni pertrechos en buen estado, y los mandos oficiales omitieron la realización de labores de inteligencia. Adicionalmente, una vez iniciado el ataque, la guarnición debió soportarlo sin recibir ayuda alguna (esta llegó cuando los daños ya se habían concretado), a pesar de la cercanía relativa de diversas bases militares.

Ahora bien, inicia la Sección Tercera recordando que las personas incorporadas coercitivamente a las FFAA en cumplimiento del servicio militar obligatorio, tienen la doble condición de ciudadanos-soldados. De esto se deriva que estas personas no hayan asumido voluntariamente los riesgos inherentes al desempeño de la actividad militar, por lo que su situación no es igual a la de los soldados profesionales

La Sala hace una recopilación jurisprudencial, estableciendo que para los casos en que conscriptos se vean afectados con ocasión del conflicto armado los tres títulos de imputación son aplicables, dependiendo de las variables de cada caso. En primer lugar, habrá falla del servicio si se comprueba que las autoridades fallaron en la protección de sus propios hombres, debido a negligencia y errores evidentes que hayan contribuido de forma certera en la ocurrencia del daño. Tal situación la considera comprobada en el caso. En segundo lugar, considera que, en ciertas ocasiones, el título de imputación podrá ser el riesgo excepcional, en tanto a los conscriptos se les haya puesto en una situación de riesgo extraordinario en perjuicio de sus derechos fundamentales. Este hecho lo considera probado a su vez, al estimar que la ubicación de la base militar constituía un riesgo apreciable para la integridad de los soldados. Por último, cuando los hechos no se encuadren en los títulos anteriores, el Estado será responsable por daño especial. Su configuración se da en tanto al soldado regular se le pone en una situación donde el equilibrio de las cargas públicas se rompe, puesto que los derechos del soldado ceden ante el bienestar general y la defensa del orden constitucional.

A pesar de lo anterior, y que en el caso se notaba claramente que el sustento para la condena lo constituía la falla del servicio, la Sala confunde su argumentación al intentar usar como título la posición de garante y la creación de una situación objetiva de riesgo, siendo que estos elementos constituyen el nexo (mediante imputación objetiva). Esta apreciación es desarrollada en aclaración de voto por el Consejero Enrique Gil Botero.

De esta forma, la Sección considera que la omisión del Estado participó en la creación del daño, al desconocer su posición de garante de la integridad de los soldados, olvidando el art. 2 de la Constitución, y sus deberes internacionales en la protección de los derechos humanos. Por último, al analizar la causal de exoneración del hecho del tercero, considera que ante la existencia de la posición de garante y el consiguiente deber de actuar desdibuja completamente la excepción, dado que es exactamente esa actuación por parte del tercero la que se debía impedir, omisión que genera responsabilidad. 


\section{Militar incorporado a filas voluntariamente}

Los dos últimos casos corresponden a aquellos en que la víctima era un militar voluntariamente incorporado a las FFAA. En la primera sentencia, exp. 19195, la víctima era un policía que murió en medio del ataque de las FARC contra la estación de Barbacoas, Nariño, el 6 de junio de 1997. En esta acción fallecieron varios policías y el resto fueron secuestrados por el grupo insurgente.

Las instalaciones policiales eran inadecuadas pues no habían sido completadas, siendo difícil su defensa. Adicionalmente, las fuerzas policiales tenían conocimiento de la amenaza que representaba la presencia del grupo insurgente en la zona, por lo que se dispuso el incremento del pie de fuerza y apoyo logístico. Sin embargo, los policías no tenían la munición adecuada y no recibieron el apoyo a tiempo, lo que permitió que la guerrilla redujera a un número considerable de uniformados. Aunado a lo anterior, el puesto policial había sido hostigado con anterioridad (abril del 97).

Teniendo lo anterior en mente, la Sala recuerda que cuando se trata de daños causados por terceros a personal de las fuerzas de seguridad del Estado incorporadas voluntariamente, el único título de imputación procedente es la falla del servicio. Aparte de verificar los elementos comunes de la falla, se añade otro elemento necesario, en tanto los militares incorporados voluntariamente aceptan un margen de riesgo inherente a la actividad que realizan. Este elemento hace que los daños producidos dentro de ese margen no puedan enmarcarse dentro de la responsabilidad del Estado ${ }^{26}$, salvo que estos se deban a una falla del servicio o a la exposición de las víctimas a riesgos excepcionales ${ }^{27}$. Tal circunstancia fue acreditada en el caso.

Ahora bien, en cuanto al nexo de causalidad, se acude a la posición de garante, entendida como el deber de protección de los derechos humanos de los funcionarios estatales. A pesar de lo cual y conociendo la situación de amenaza que se cernía sobre estos, el Estado no llevó a cabo las medidas necesarias para por lo menos atenuar los daños antijurídicos que se presentaron con la toma de la Estación. Situación reprochable por cuanto se dejó a los policías en un estado de indefensión y sin apoyo ante el ataque masivo del grupo insurgente. De esta forma, a través del mismo sustento argumentativo rechaza el hecho de tercero como causal de exoneración en el caso, al ser la omisión de la administración determinante en la causación del daño. En consecuencia, se encontraron configurados los elementos que hacían procedente la condena patrimonial ala Policía Nacional.

El último caso de la categoría y del estudio presente corresponde al exp. 17138. En este, se solicita la condena del Ejercito Nacional a título de falla del servicio, ante la muerte de un militar por parte de sicarios, ocurrida en Medellín en 1989. Este funcionario fue objeto de repetidas amenazas a su vida por la labor adelantada

26 Estos daños han sido cubiertos por la denominada indemnización a forfait, como especie de régimen prestacional especial que la ley establece para los miembros de las FFAA.

Entendido como aquellos que sobrepasan a los que normalmente están sujetos los militares. 
en contra de los carteles del narcotráfico. Se le asignó un dispositivo de seguridad (sin ser claro cómo estaba compuesto), se le recomendó no visitar ciertos lugares y se ordenó su traslado a la base militar de Tolemaida, traslado a realizarse el día en que resultó asesinado. El delito se presentó en una zona de alto riesgo, a donde llegó con su novia y su esquema de seguridad. Este último no entró al establecimiento y permaneció en la zona de parqueo. Una vez ubicados en una mesa, a los pocos minutos se acercó el victimario, propinándole cerca de trece disparos sin que la escolta se diera cuenta de lo ocurrido. Por último, debe tenerse en cuenta que la víctima no estaba armada; su arma de dotación le había sido retirada ante el traslado a Tolemaida.

En cuanto al título de imputación, se recuerda que solo la falla del servicio es aplicable, sin perder de vista el concepto del riesgo inherente a la profesión militar. Adicionalmente, se retoman los elementos con respecto a la omisión, utilizados en casos anteriores, frente a cuando surge el deber de protección del Estado, dado su conocimiento de las amenazas que pesaban sobre el soldado. Cabe aclarar que el reproche hecho por el Consejo no se refiere a la idoneidad de las medidas de protección preparadas por la administración, sino al hecho comprobado de que estas fallaron estrepitosamente por la negligencia de los agentes estatales dispuestos para la protección de la víctima, además del hecho inexplicable de haberle retirado el arma de dotación oficial, por lo que se considera configurada la falla.

En cuanto al nexo de causalidad, no se siguen los precedentes existentes frente a la imputa- ción objetiva ni se hace un análisis detallado, a pesar de que se evidencia cierto sustento similar a la posición de garante de la administración.

Por último, frente a las causales de exoneración, no se analiza la del hecho del tercero, que es rechazada de plano ante la comprobación de la omisión de la administración. Sin embargo, el caso presentaba una causal adicional, consistente en el hecho exclusivo de la víctima, sustentada, según la defensa, en que el soldado se expuso imprudentemente a una situación de riesgo. En este punto, si bien se acepta que el soldado sí se expuso imprudentemente, esta negligencia no era exclusiva ni desaparecía la de la administración, generándose la presencia de dos causas del daño. En consecuencia, aplica el art. 2357 del Código Civil ${ }^{28}$, aminorando la condena contra la entidad.

\section{Conclusiones preliminares}

La jurisprudencia del Consejo de Estado, a partir del art. 90 de la Constitución, ha desarrollado diversos títulos de imputación que permiten asignar la reparación de un daño antijurídico al Estado. Cuando tales daños son causados desde el punto de vista material por el accionar de grupos violentos ajenos al Estado, es posible asignar la reparación a la entidad estatal si se configuran tales títulos, en conjunto con un correspondiente nexo de causalidad con el daño antijurídico.

28 Código Civil, artículo 2357. <REDUCCION DE LA INDEMNIZACION>. La apreciación del daño está sujeta a reducción, si el que lo ha sufrido se expuso a él imprudentemente. 
El título de imputación utilizable dependerá de la calidad de la víctima del hecho dañoso, es decir, si es un civil, un conscripto o un militar incorporado voluntariamente. En el primer caso, el título corresponderá a la falla por omisión del servicio de protección, para lo cual habrá de demostrarse, aparte del daño y el nexo, la ocurrencia de alguna de las siguientes situaciones: a) que se haya dejado a la población a merced de los grupos delincuenciales, sin prestar protección, en especial si es de conocimiento público la violación de derechos por parte de estos grupos; b) que se haya solicitado protección especial por parte de la víctima y no se haya actuado; c) que no se solicitó expresamente dicha protección pero era evidente su necesidad ante las condiciones de amenaza en que se encontraba la víctima. El Consejo de Estado considera que el fundamento normativo del deber de protección es el art. 2 de la Constitución, así como los instrumentos internacionales que obligan al Estado colombiano a la protección de los derechos humanos.

En cuanto a los conscriptos, el título utilizable dependerá de las especiales circunstancias del caso, debiéndose declarar la falla si esta se presenta, o sustentar la responsabilidad en el riesgo si el resultado proviene de la concreción de alguno creado por la administración. Por último, será factible el uso del daño especial si no se puede enmarcar la situación en los anteriores, en tanto que el daño antijurídico que afecta a los ciudadanos-soldados destruye el equilibrio de las cargas públicas e impone el deber de reparación.

Cuando la víctima sea un militar incorporado voluntariamente a las fuerzas militares solo es procedente la falla del servicio. Esto en el entendido que los mismos aceptan con su vinculación la asunción de una serie de riesgos para su integridad que, en principio, no comprometen la responsabilidad del Estado. Solo si se da una falla o hay una exposición a un riesgo excepcional, es procedente la declaratoria de responsabilidad.

En cuanto al nexo de causalidad, si bien no se usan las teorías clásicas (equivalencia de condiciones y causalidad adecuada), hay un progresivo uso de la imputación objetiva y en especial de la posición de garante para asignar la producción de un daño al Estado. Cabe anotar que no todas las sentencias hacen un juicioso análisis del nexo, por lo que se denota cierta falta de rigurosidad en algunos casos. Respecto a la posición de garante, el Consejo de Estado es constante al considerar que el Estado ostenta tal calidad en cuanto a la protección de los derechos humanos, tanto de civiles, como de militares, por lo que no ejecutar medidas de protección o aminoramiento de las amenazas a tales derechos puede comportar responsabilidad de la administración.

Finalmente, se evidencia que el Consejo de Estado no es muy riguroso a la hora de evaluar las causales de exoneración propuestas por la defensa del Estado, en particular el hecho de un tercero. En todo caso se evidenció que la obligación de actuar y la posición de garante hacen responsable al Estado, justamente por haber permitido que un tercero causara un daño. 


\section{CASOS A RESOLVER}

Ya ha comprendido el lector cuál es la posición actual del Consejo de Estado frente a la asignación de responsabilidad a la administración, respecto de los daños cuyo origen material proviene del accionar de terceros. Sin embargo, persiste la duda investigativa que sustenta este texto, es decir, cómo se resolverían los casos en que se endilga responsabilidad al Estado por los daños antijurídicos causados materialmente por terceros actores del conflicto armado, y si esta solución sería o no favorable a los eventuales demandantes. El propósito del presente capítulo es, entonces, responder tal pregunta mediante la exposición de dos casos reales de secuestro cometidos por actores del conflicto, proponiendo una posible solución desde lo encontrado en el capítulo anterior.

Estos dos casos corresponden al secuestro de policías y militares durante la toma, en noviembre de 1998, de la ciudad de Mitú (Vaupés), y el secuestro en febrero de 2002 de la excandidata a la Presidencia de la República Ingrid Betancourt, ambos cometidos por las farc. Fueron seleccionados por su especial relevancia, al ser dos hechos notorios y conocidos del conflicto armado en nuestro país en los últimos años. En primer lugar, la toma de Mitú marcó especialmente el inicio del fracasado intento de paz llevado a cabo durante la presidencia de Andrés Pastrana Arango, ${ }^{29}$ pues ocurrió justo antes del comienzo de la zona de distensión, además de ser la primera y única ocasión en que las farc

29 La acción tuvo lugar una semana antes del inicio del proceso de paz. ocupaban una capital departamental (Semana, noviembre 1998, p. 51). Adicionalmente, y esto en relación con la primera parte del texto, durante la toma resultaron afectados tanto militares incorporados voluntariamente a las FFAA como conscriptos, lo cual permite cubrir dos de las categorías analíticas expuestas.

Por su parte, el secuestro de Ingrid Betancourt resulta especialmente interesante en su descripción y la posible solución a dar, teniendo en cuenta el impacto que tuvo en la opinión pública nacional e internacional, por las particularidades en que se presentó, ${ }^{30}$ así como por el "escándalo" causado por la decisión de la señora Betancourt de demandar al Estado colombiano. ${ }^{31}$

La estructura de exposición de los casos comienza con el establecimiento de unos hechos mínimos relevantes, a partir de las notas de prensa publicadas en su momento por los diarios más importantes, ${ }^{32}$ así como notas publicadas con posterioridad, que dan cuenta de la dinámica de estos hechos. Enseguida se propondrá

30 El secuestro ocurrió el día después de ser levantada la zona de distensión, hecho a su vez provocado por el secuestro de Jorge Eduardo Gechem Turbay, el 22 de febrero de 2002.

31 Betancourt y su familia presentaron solicitud de conciliación ante la Procuraduría General de la Nación el 30 de junio de 2010, citando a la Nación-Ministerio de Defensa (en representación del Ejército y la Policía) y a la Nación-Ministerio del Interior. Ante esto el Gobierno Nacional públicamente rechazó la solicitud, enfocando su posición en mostrarla como un ataque a las FFAA y una actitud desleal con los soldados que la habían rescatado durante la "Operación Jaque". Ante las constantes críticas recibidas, Betancourt desistió y retiró la solicitud el 13 de julio del 2010. Para más información consultar: América Economía, 9 de julio del 2010 y EL, Ingrid Betancourt retira..., 13 de julio del 2010.

32 Para la toma de Mitú se utilizan reportes de los diarios El Tiempo y El Espectador, junto con la revista Semana. En el caso de Betancourt no se utilizó El Espectador, puesto que para la fecha no era de publicación diaria, y en las ediciones de las semanas posteriores tampoco se pudo encontrar artículos sobre su secuestro. 
la solución a cada caso, revisando el título de imputación, el nexo de causalidad, las posibles causales de exoneración para la defensa del Estado, y la hipotética solución a la que llegaría el Consejo de Estado.

\section{A. Mitú}

Mitú es una pequeña ciudad de no más de diecisiete mil habitantes (Mitú, Nuestro..., s.f.), ubicada sobre los márgenes del río Vaupés. Es la capital del departamento homónimo desde 1963 -en ese entonces Vaupés era comisaría- (Mitú, Historia..., s.f.). Se encuentra en un lugar no lejano a la frontera con Brasil y a más de 660 kilómetros de Bogotá. La dependencia del transporte aéreo y fluvial, y la inexistencia de vías de comunicación terrestres, la convierten en una población aislada de la mayor parte del país y de los grandes centros poblacionales y económicos (Mitú, Vías..., s.f.). Para la fecha de la toma, contaba con cerca de quince mil habitantes y era resguardado únicamente por un contingente de 120 policías, entre profesionales y conscriptos, comandados por el entonces coronel Luis Mendieta, sin que hubiera presencia o apoyo del Ejército Nacional (Ardila, 21 abril 2008). Esta suma de factores hacía de la ciudad un sitio especialmente vulnerable, tanto así que en la revista Semana (noviembre 1998, p. 52) se reportaba que "en esas condiciones lo raro es que las Farc no se hubieran tomado Mitú antes".

Ahora bien, el primer grupo de noticias que permite reconstruir la toma son las publicadas por Ios diarios El Espectador y El Tiempo el 2 de noviembre de $1998 .{ }^{33}$ Este día, habían pasado solo 24 horas desde el inicio de la toma, la información era fragmentaria, en tanto provenía únicamente de las FFAA y de comunicaciones vía celular con personas presentes en el municipio. Se reportaba entonces que el asalto había comenzado alrededor de las 5:00 a.m. del 1 de noviembre, mediante el ataque coordinado de más o menos 800 a 1000 guerrilleros del Bloque Oriental de las FARc. Los guerrilleros utilizaron pipetas de gas, granadas, ametralladoras y otros armamentos, concentrando su fuego contra la estación de policía y la sede de la Caja Agraria. Adicionalmente, bloquearon el acceso a la población, dinamitando la pista del aeropuerto, incinerando aeronaves y destruyendo las torres de comunicación. Por su parte, los 120 policías correspondían a 90 profesionales (los que la jurisprudencia denomina voluntarios) y a 30 auxiliares de policía, es decir, ciudadanos que prestaban su servicio militar. Se defendían con lo disponible, y uno de ellos pudo informar a Bogotá sobre lo que ocurría.

Los altos mandos militares, encabezados por los generales de la policía Rosso José Serrano y Luis Ernesto Gilibert, y el general Fernando Tapias, comandante de las Fuerzas Militares, iniciaron las labores para el apoyo a los sitiados y la recuperación de Mitú. El apoyo establecido consistió en el envío del denominado Avión Fantasma, diez helicópteros Black Hawk, y avio-

33 Las notas consultadas son: (EL, Mitú, bajo..., 2 noviembre 1998); (EL, Mil guerrilleros..., 2 noviembre 1998); (EL, El ataque de ayer..., 2 noviembre 1998); (ET, Las Farc arrasaron..., 2 noviembre 1998); (ET, Sangrientos combates..., 2 noviembre 1998); (ET, Información es precaria..., 2 noviembre 1998). 
nes de combate OV-10, ${ }^{34}$ así como el despacho de tropas desde Villavicencio y la base aérea de Apiay (ubicada a 500 kilómetros de Mitú). A pesar de esto, las ediciones de ese día reportaban la imposibilidad de las FFAA para recuperar la ciudad, dada la situación del aeropuerto y la evidente dificultad de acudir con refuerzos hasta un lugar tan alejado. Así mismo, había una total incertidumbre sobre la suerte de los policías: los rumores hablaban de la muerte de un número elevado de estos y de la captura de otros tantos.

Esta incertidumbre se desvaneció el 3 de noviembre $^{35}$ cuando los diarios comenzaron a reportar la suerte de los uniformados, reproduciendo las palabras de Teddy Tormbaum, presidente de la seccional Meta de la Cruz Roja, quien había estado presente durante la toma e informaba sobre el secuestro de alrededor de 45 policías (sin especificar su categoría) y la muerte de los restantes; la Cruz Roja no había encontrado heridos. Aparte de lo anterior, cabe resaltar que las FARC aún tenían el control de la ciudad. Los soldados del Ejército Nacional habían podido llegar a la zona solo hasta las 8:15 a.m. del 1 de noviembre, luego de desembarcar en la pista Quererí, ubicada en territorio brasileño, a 60 kilómetros de Mitú.

El Tiempo reportó el envío de dos aviones, mientras El Espectador hablaba de cinco.

35 Las noticias consultadas son: (EL, Holocausto..., 3 noviembre 1998); (EL, "Se defendieron ..., 3 noviembre 1998); (EL, Tropas combaten..., 3 noviembre 1998); (EL, "Policía de Mitú no..., 3 noviembre 1998); (EL, Repeler a los guerrilleros..., 3 noviembre 1998); (EL, El drama que se repite..., 3 noviembre 1998); (ET, Incierta..., 3 noviembre 1998); (ET, Apoyo Aéreo..., 3 noviembre 1998); (ET, En un basurero..., 3 noviembre 1998); (ET, Cruel Batalla..., 3 noviembre 1998); (ET, Fue imposible..., 3 noviembre 1998); y (ET, La policía de Mitú..., 3 noviembre 1998)
Adicionalmente, empezaron a aparecer dos versiones que resultan muy importantes a efectos de establecer la responsabilidad por los hechos. En los dos diarios se reportaba que los pobladores indicaban que este era un ataque anunciado pues los rumores de la toma venían circulando varios días antes y, supuestamente, las farc habían dado aviso a los civiles para que se retiraran del casco urbano antes del inicio de los hechos. En adición se publican las declaraciones de la representante a la Cámara por el Vaupés, María Eugenia Jaramillo, en las que denunciaba que los policías de Mitú no conocían la zona y no se hallaban preparados para una incursión guerrillera, palabras que fueron interpretadas como un primer reproche a la actuación de las FFAA (ET, La policía de Mitú..., 3 noviembre 1998).

Para el 4 de noviembre ${ }^{36}$ los diarios seguían haciendo un cubrimiento continuo de la toma y entre lo más relevante figuraba el hecho de que las FFAA no habían podido recuperar la ciudad, la protesta por parte del gobierno del Brasil por haber invadido su territorio para facilitar la retoma, la publicación de los nombres de los uniformados retenidos y la confirmación de que las FARC se habían llevado a los auxiliares de policía ${ }^{37}$. Fi-

36 Las noticias consultadas son: (EL, Mitú, 72 horas..., 4 noviembre 1998); (EL, El Gobierno seguirá..., 4 noviembre 1998); (EL, Aun no existe..., 4 noviembre 1998); (EL, "Operación Marquetalia..., 4 noviembre 1998); (EL, Nos dejaron avanzar..., 4 noviembre 1998); (EL, Incertidumbre..., 4 noviembre 1998); (EL, Incierto el número..., 4 noviembre 1998); (EL, Los 30 auxiliares..., 4 noviembre 1998); (ET, Batalla nocturna..., 4 noviembre 1998); (ET, Un coronel en poder..., 4 noviembre 1998); y (ET, Colombia violó..., 4 noviembre 1998).

37 Dentro de los uniformados capturados se reportaban el coronel (general) Luis Herlindo Mendieta, el capitán (mayor) Julián Ernesto Guevara, y el subintendente John Frank Pinchao. (EL, Los 30 auxiliares..., y ET, Un coronel en poder..., 4 noviembre 1998). 
nalmente, la prensa del 5 de noviembre ${ }^{38}$ reporta la recuperación de la ciudad por parte de las FFAA, los daños causados por la toma (destrucción de los edificios gubernamentales y civiles cercanos), y la retirada de las FARC con un número considerable de uniformados secuestrados.

Ahora bien, es posible resumir la toma en los siguientes hechos relevantes: Mitú, para el 1 de noviembre de 1998, era resguardada por una guarnición de 120 policías, entre profesionales y auxiliares bachilleres. En tal fecha un grupo de entre 800 y 1000 guerrilleros atacaron la ciudad con pipetas de gas y otros tipos de armas, con el objetivo de ocupar el municipio, ataque que comenzó hacia las 5:00 a.m. Este duró cerca de 24 horas y dejó como saldo un número considerable de uniformados fallecidos y alrededor de 45 secuestrados, entre ellos un grupo de 30 auxiliares bachilleres y los oficiales Luis Mendieta, Julián Guevara y John Frank Pinchao.

El alto mando militar tuvo conocimiento de la toma el mismo 1 de noviembre y dispuso un plan de apoyo compuesto por aviación y tropas, que solo pudieron llegar a una localidad brasileña cercana tres horas después (a las 8:15 a.m.). Dada la lejanía y la afectación del aeropuerto (única vía de entrada), el Ejército retomó el control de la ciudad solo 72 horas después de iniciada la toma, sin poder evitar el secuestro de los uniformados.

38 Las noticias consultadas son: (EL, Mitú, desolada, 5 noviembre 1998); (EL, Regreso a rastras..., 5 noviembre 1998); (EL, Sobrevivientes, muertos..., 5 noviembre 1998); (EL, Mitú hoy no es nada..., 5 noviembre 1998); (EL, Queremos ir..., 5 noviembre 1998); (ET, Toma y destrucción..., 5 noviembre 1998); (ET, Así recuperaron...,5 noviembre 1998); (ET, Por qué Mitú, 5 noviembre 1998); (ET, Rabia y dolor..., 5 noviembre 1998); y (ET, Identifican cuerpos..., 5 noviembre 1998).
Según algunas versiones, la toma fue anunciada y la población sabía lo que ocurriría. Por otra parte, existen indicios sobre la poca preparación del conjunto policial para resistir una toma guerrillera.

Estos hechos serán la base del ejercicio a realizar, no sin antes recordar la limitación que presenta la prensa para reconstruir los verdaderos hechos de la toma. En un eventual proceso, será de carga de los demandantes la prueba de aquellas situaciones que les faciliten la sustentación de sus posiciones, y cuya averiguación escapa a las posibilidades del autor.

\section{Solución}

Hechas las precisiones correspondientes, se procede al análisis propuesto comenzando por la categoría militares incorporados a filas voluntariamente, para luego revisar la categoría conscriptos, solo frente al título de imputación, al ser el único elemento de diferencia. Tanto en uno como en otro caso se entenderá que la acción contenciosa es ejercida por los mismos secuestrados después de su liberación. Por su parte, vistas las entidades involucradas en los hechos, los demandados serían tanto la Policía Nacional como el Ejército Nacional, ambos representados jurídicamente por la Nación-Ministerio de Defensa.

a. Frente a los militares incorporados voluntariamente

En las definiciones del Capítulo 1 se explicó que el primer elemento a revisar en cualquier caso de responsabilidad, por ser su umbral mínimo, es 
la ocurrencia de un daño antijurídico sufrido por una persona. Este daño tiene que ser probado por los demandantes, en aplicación del art. 177 del Código de Procedimiento Civil, por remisión del art. 267 del Código Contencioso Administrativo (306 de la Ley 1437). En el caso de Mitú, es evidente que del hecho dañoso del secuestro cometido por las FARC contra policías como el coronel Mendieta o el mayor Guevara, derivan una serie de daños antijurídicos incontestables, considerada la naturaleza misma del delito cometido sobre estos. Para efectos de este texto y dado su objetivo, se presumirá la ocurrencia de daños antijurídicos y de una serie de perjuicios derivados del secuestro. No hay discusión alguna frente a que la privación injusta de la libertad comporta daños en diversos niveles, que no podrían calificarse como "jurídicos".

Hecha esta aclaración, se debe revisar el título de imputación cuya verificación permitiría asignar responsabilidad al Estado. Como se vio en los exp. 19195 y 17138, el Consejo de Estado ha establecido que el único título utilizable en estos casos es la falla en el servicio, al exponer a los militares a riesgos que superan aquel que aceptan con su vinculación a las FFAA. De esta forma, solo si los hechos evidencian una acción u omisión grosera de la administración que ha puesto a sus propios hombres en una situación que supera ese riesgo tolerado al entrar a formar parte de la fuerza pública, el Estado sí puede ser responsable de los daños causados. En caso contrario, la reparación de los daños sufridos queda cubierta por la indemnización a forfait.
Ahora bien, en el caso de Mitú, vemos, por una parte, que los policías no tenían apoyo del Ejército previo a la toma y que eran un contingente muy pequeño y sin armas suficientes para resistir una toma guerrillera. Adicionalmente, algunas versiones apuntan a cierta falta de preparación y al desconocimiento de la zona y a cierto conocimiento de la posibilidad de una toma guerrillera. A favor de la actuación del Estado tenemos que la reacción en apoyo de los sitiados por parte de las FFAA fue muy rápida, buscando recuperar la población inmediatamente. Eso sí, se encontró con inmensas dificultades tácticas y estratégicas que impidieron la retoma por 72 horas y que en cierta medida facilitaron el secuestro de los policías.

La comparación de estos elementos, puestos a la luz del concepto de relatividad de la falla del servicio, evidencia que el Consejo de Estado podría inferir tanto la existencia como la inexistencia de la falla. Las limitaciones que impone la reconstrucción de los hechos a partir de la prensa, donde se escapan muchos elementos que podrían llegar a estar dentro del material probatorio en un juicio, no permiten identificar sin lugar a duda la ocurrencia o no de la falla. En todo caso, dentro de la posición personal del autor, considero que sí se presentó una falla en el servicio, que evidencio a través de tres preguntas: ¿Por qué una guarnición de policías tan pequeña y no tan bien equipada se encontraba en la obligación de cuidar una capital departamental? ¿Por qué no había presencia del Ejército Nacional en la ciudad antes de la toma? ¿Por qué tardó tres días recuperar la ciudad, facilitando así que las farc se llevaran a los secuestrados? 
De esta forma, la falla de la administración participó en la concreción del resultado dañoso cometido materialmente por las FARC, produciendo una afectación muy grave a unos policías en el cumplimiento de su deber, lo que supera el riesgo normal en el ejercicio de su labor e impone el deber de reparación a cargo del Estado.

Visto lo anterior, el tercer elemento a analizar corresponde al nexo de causalidad. Como se vio en los casos explicados en la categoría y se evidenció también en algunos de los otros presentados, más allá que preguntarse sobre el vínculo material entre la falla de la administración y el daño, se debe cuestionar el vínculo jurídico y obligacional entre estos, es decir, si el Estado tenía una posición de garante respecto de los uniformados secuestrados. En el exp. 19195 se recuerda que el Estado tiene una posición de garante respecto a los derechos humanos de sus funcionarios, por lo que dejarlos a merced de un grupo delincuencial vincula la falla con la afectación de los derechos de los uniformados. Este razonamiento, en caso de encontrar configurada la falla, sería aplicado por el Consejo de Estado en tanto se puede afirmar que el Estado es garante del respeto del derecho a la libertad e integridad de los policías, derechos vulnerados con su secuestro, por lo que la falla sí se encontraría vinculada al daño sufrido por los secuestrados. Esta misma consideración haría despachar por inconsistente la excepción del hecho del tercero, en tanto era exactamente ese hecho el que ha debido evitarse por ser ajeno a la acción y omisión de la administración.

Vistos los anteriores elementos, y tomando la posición personal expresada en párrafos ante- riores, frente al secuestro de policías durante la toma de Mitú, el Consejo de Estado condenaría a las dos entidades a reparar los daños antijurídicos ocurridos con ocasión de estos secuestros, ante la verificación de una falla en el servicio a ellas imputable por violación de su posición de garantes respecto de sus propios miembros.

b. Frente a los conscriptos

Ahora bien, frente a los ciudadanos-soldados secuestrados durante la toma, en su casi totalidad auxiliares de policía indígenas, cabe anotar que el daño antijurídico sería el mismo (y por ende se presume en este texto), pero las consideraciones frente al título de imputación serían diferentes.

Como se vio en las sentencias de Las Delicias, frente a los conscriptos es posible hacer el juicio de imputación desde cualquiera de los tres títulos desarrollados por la jurisprudencia. Si se apunta a la posición de que sí se presentó una falla en el servicio, es este el título que sustentaría la responsabilidad del Estado en este caso, sin diferencia alguna con lo ya explicado en el punto anterior. En caso contrario, primero debe revisarse si el caso se encuadra en el riesgo excepcional o, en última instancia, en el daño especial.

El riesgo excepcional consiste en la concreción de un riesgo usualmente previsible, que se genera a partir del ejercicio de una actividad o de la utilización de cosas usualmente consideradas como peligrosas. La actividad o cosa entraña el riesgo en sí misma, por lo que su concreción hace responsable a aquel que deriva un provecho de su ejercicio o utilización. De esta forma, 
para su aplicación ha de identificarse una actividad o cosa peligrosa como fuente del riesgo y un hecho que sea su concreción.

Vistos los hechos de la toma de Mitú, frente a los policías, que eran quienes ejercían una actividad que eventualmente puede ser considerada como peligrosa, pero respecto a los individuos externos a la misma. Además, teniendo en cuenta que el ejercicio de la labor policial, así sea impuesto por el ordenamiento, implica la asunción de ciertos riesgos, sería incoherente utilizar este título de imputación para asignar la responsabilidad al Estado.

Resta entonces evaluar si es aplicable el título de daño especial. Las sentencias de Las Delicias muestran que este título de imputación se impone en aquellos casos donde no hay falla ni se puede hablar de riesgo, pero sí se genera un daño antijurídico impuesto solo a un grupo o persona en especial, rompiendo con el equilibrio de las cargas públicas. Ahora bien, el Consejo de Estado considera que el servicio militar obligatorio impone una serie de deberes sobre el conscripto en beneficio de la sociedad, por lo que en caso de perjuicios causados a estos la equidad impone al conglomerado social la reparación, restableciéndose el equilibrio roto. En este orden de ideas, si se considera que la actuación estatal no constituyó falla ni es la concreción de un riesgo, los perjuicios sufridos por los conscriptos deberían ser reparados por el Estado a título de daño especial.

Finalmente, en cuanto al nexo de causalidad, a pesar de que las sentencias de Las Delicias no son juiciosas en este punto, los otros casos ana- lizados nos indican que se debe verificar si hay una posición de garante por parte del Estado y si su vulneración vincula la actuación estatal al daño. Al igual que en el punto anterior e incluso más claramente, es evidente que el Estado tiene una posición de garante de la integridad y derechos de los conscriptos a su cargo, por lo que el haber permitido la ocurrencia de la toma y la captura de estos, rompe esta posición y compromete la responsabilidad del Estado. En consecuencia, sea a título de falla en el servicio o a título de daño especial, el Estado sería responsable por los daños antijurídicos causados a los auxiliares de policía secuestrados en Mitú, imponiéndose la reparación.

\section{B. Ingrid Betancourt}

Ingrid Betancourt es una política colombiana, nacida en Bogotá en 1961, del matrimonio entre el exministro Gabriel Betancourt y la exsenadora Yolanda Pulecio. Educada en Francia, regresó al país en 1989 para ocupar diversos cargos gubernamentales durante el mandato presidencial de César Gaviria (Betancourt, 2010). En 1994 fue representante a la Cámara por el Partido Liberal, destacándose como crítica del gobierno Samper y del sonado "Proceso 8000" sobre infiltración de dineros del narcotráfico en la campaña presidencial del 94 (ET, Ingrid, una candidata..., 25 febrero 2002). Para 1997 fundó su propio movimiento político, Oxígeno Verde. En 1998 fue elegida como senadora, posición a la que renunció para presentarse como candidata a la Presidencia de la República en las elecciones del año 2002, en las cuales resultó elegido Álvaro Uribe Vélez. 
Durante el proceso electoral y tres días después del levantamiento de la zona de distensión del Caguán ante el secuestro de Jorge Eduardo Gechem (Semana, marzo 2002, p. 26), fue secuestrada a su vez por las FARC cuando se dirigía hacia San Vicente del Caguán desde la ciudad de Florencia. Su secuestro duró cerca de seis años y medio, y finalizó al ser rescatada durante la renombrada "Operación Jaque" realizada por el Ejército Nacional (Semana, ¡Ingrid, los tres... . 2 julio 2008).

El recuento periodístico de este secuestro comienza con la nota Desaparecida, Ingrid Betancourt, publicada en el diario El Tiempo el 24 de febrero de 2002, donde se indica el desconocimiento sobre la suerte de la candidata, luego de haber salido a la 1:15 p.m. de Florencia, por vía terrestre, con destino a San Vicente del Caguán y de perder contacto con su comitiva antes de llegar a El Paujil. Según los organismos de seguridad (no se especifica cuáles), no fue posible su traslado vía aérea por problemas logísticos y la candidata insistió en su viaje a pesar de las advertencias sobre la difícil situación de seguridad.

La incertidumbre sobre su paradero desaparece el 25 de febrero ${ }^{39}$, cuando se confirma su secuestro por parte del grupo insurgente. En la nota Así fue el secuestro de Ingrid Betancourt, se hace un recuento pormenorizado de las circunstancias del delito, donde se destacan los siguientes puntos: a) Betancourt llegó a Florencia a las 10:40 a.m. del 23 de febrero y solici-

39 Ese día se publica un buen número de noticias sobre Betancourt, a saber: (ET, Asi fue el secuestro..., 25 febrero 2002); (ET, Ingrid: una candidata..., 25 febrero 2002); (ET, El secuestro de Ingrid oscurece..., 25 febrero 2002); (ET, Se enrarece..., 25 febrero 2002); y (ET, ONU condena..., 25 febrero 2002). tó un cupo dentro de la comitiva presidencial que también se trasladaría a San Vicente del Caguán; b) su solicitud fue rechazada por los militares, arguyendo el estado de guerra en ese sitio y que tal ayuda constituiría una indebida intervención en política; c) la candidata desoyó las advertencias sobre su seguridad y partió de la ciudad hacia la 1:00 p.m. en un vehículo facilitado por el Departamento Administrativo de Seguridad (DAS); d) Betancourt pasó por el retén militar del batallón de ingenieros Liborio Mejía, donde supuestamente se le advirtió de retenes guerrilleros, pero continuó el recorrido haciendo caso omiso a la advertencia; e) hacia las 2:00 p.m. fue retenida por guerrilleros en un sitio cercano a El Paujil, donde habían bloqueado la vía con carros bomba; f) en el momento de la retención, un guerrillero pisó una mina "quiebrapatas", por lo que fue subido a la camioneta del DAs, que debió dirigirse con el grupo (secuestrados y guerrilleros) a un sitio donde los esperaban dos camionetas, una donde fueron subidas Betancourt y Clara Rojas, mientras que en la otra fueron puestos los demás retenidos; g) los otros acompañantes fueron liberados, ignorándose el destino de Betancourt y Rojas. El resto de noticias registran las diversas reacciones en el país por el secuestro, entre las cuales se destaca la reacción del ministro del Interior, Armado Estrada Villa, quien veladamente calificó las decisiones de Betancourt como indiscretas e imprudentes.

Las circunstancias descritas desataron una polémica nacional, en cuanto a quién le asistía responsabilidad por el secuestro. El Tiempo (Debate por..., 26 febrero 2002) toma nota de la situación evidenciando las dos posiciones mayo- 
res en el asunto: la del ministro del Interior que critica la actuación de Betancourt en comparación con la de los otros candidatos presidenciales que planeaban ir al Caguán pero cancelaron el viaje ante las advertencias de inseguridad, y aunque no dice que la candidata fue la responsable sí reafirma que desatendió las recomendaciones hechas; en el otro extremo se encuentran los miembros de la campaña presidencial de Betancourt, quienes no solo critican la posición gubernamental y le piden que asuma su responsabilidad, sino que aseveran que la negligencia oficial forzó el peligroso viaje por tierra. Por su parte, un columnista de El Tiempo - que no aparece identificado en el archivo del diario- sin dejar de resaltar la imprudencia de Betancourt se suma a esta posición, recriminándole al gobierno que no podía lavarse las manos por haber hecho advertencias de seguridad y que era sensata la exigencia de garantías y colaboración para movilizarse, por parte de la candidata (ET, Atentado contra..., 26 febrero 2002).

Visto lo anterior, los hechos relevantes son los siguientes: Ingrid Betancourt era candidata por el partido Oxígeno Verde para las elecciones presidenciales del año 2002. El 20 de febrero de ese año, ante el secuestro del senador Jorge Eduardo Gechem se rompieron las negociaciones de paz entre el Gobierno y las Farc, por lo que el primero ordena la retoma de la zona de distención. Betancourt decidió visitar la región, a pesar de la difícil situación y de las advertencias de seguridad hechas por los organismos estatales.

Betancourt se desplazó a la ciudad de Florencia, desde donde partió por tierra hacia San Vicente en un vehículo facilitado por el DAS, ante la negativa de los mandos militares de transportarla en el helicóptero que llevaba a la comitiva presidencial hacia ese mismo destino. No llevaba escolta pues a esta se le ordenó acompañarla solo hasta Florencia. En el trayecto cruzó por un retén militar, donde no se le impidió el paso por razones de seguridad y donde al parecer firmó un documento asumiendo el riesgo de lo que le pudiese pasar. Cerca de El Paujil la comitiva fue interceptada por un comando guerrillero. En medio de la situación un guerrillero pisó una mina antipersonal y fue subido al carro del DAS junto con otros guerrilleros, dirigiéndose con todos los acompañantes hacia otro lugar. En otro punto, Betancourt y Clara Rojas fueron separadas de sus acompañantes e introducidas en la selva. Los demás fueron liberados.

\section{Solución}

Habiendo concretado lo necesario, resta aplicar la jurisprudencia a los hechos evidenciados para este caso. No sobra precisar que la hipotética demanda, además de dirigirse contra la NaciónEjército Nacional y Nación-Policía Nacional, ha debido incluir al DAs, dada su participación como encargado de la escolta y por haber prestado el vehículo donde se movilizó Betancourt. Al igual que en el caso anterior, se presumirán los daños sufridos por los demandantes.

Ahora bien, en cuanto al título de imputación que utilizaría el Consejo de Estado para decidir el caso, vimos en las sentencias de la categoría civil, que este sería la falla en el servicio por omisión. Para la verificación de este elemento, 
además de la demostración de la omisión que constituye falla por parte del Estado, ha de comprobarse lo siguiente: a) que se haya dejado a la víctima a merced de los grupos delincuenciales, sin prestar protección, en especial si es de conocimiento público la violación de derechos por parte de estos grupos; b) que se haya solicitado protección especial por parte de la víctima y no se haya actuado; o c) que si no se solicitó expresamente dicha protección era evidente su necesidad ante las condiciones de amenaza en que se encontraba la víctima.

En el caso de Betancourt es claro que se hizo una solicitud de acompañamiento en seguridad para su traslado a San Vicente, aunque no de forma específica, por cuanto no existía una amenaza concreta de secuestro, sino el riesgo general que compartían los candidatos presidenciales. El Estado le prestaba seguridad mediante escolta del DAS, pero a esta no se le permitió acompañarla más allá de la ciudad de Florencia. Una vez Betancourt abandonó la ciudad no contó con seguridad por parte del Estado.

Sin embargo, no puede perderse de vista la razón aducida por los servicios de seguridad para no seguir acompañando a la candidata. Se vio que la zona vivía una complicada situación de orden público, en la cual el Ejército no tenía el control del territorio y estaba en condición de conflicto abierto para recuperar la zona de distención, hecho que hacía realmente difícil prestarle seguridad a Betancourt. Eran muy sensatas las continuas advertencias y la petición de que no continuara adelante con su viaje dado el riesgo cierto (y consumado) que pendía sobre ella.
A pesar de lo anterior, hay tres elementos que hacen reflexionar sobre el papel del Estado en estos hechos. En primer lugar, la prensa indica que, en cierta forma, los detectives del DAs recibieron la orden de no acompañarla a San Vicente, pero el mismo DAs facilitó su viaje al procurarle el medio de transporte. Si existían las difíciles condiciones de seguridad, ¿por qué se le facilitó adentrarse en la "boca del lobo" a bordo de un vehículo oficial? El segundo elemento es la supuesta decisión del comandante de la policía de Florencia de permitirle viajar en helicóptero a San Vicente, decisión luego reversada. ¿Realmente el permitir tal viaje constituiría una participación en política de los militares involucrados? Si bien podría discutirse la veracidad de lo anterior, es sensato que los militares se hayan sentido cohibidos por esta posibilidad y mal se haría en exigirles poner en riesgo sus carreras. El tercer elemento es el hecho de que las autoridades, si bien continuamente advirtieron de la inconveniencia del viaje, no lo impidieron. Es cierto que todo ciudadano tiene el derecho a la libre circulación por el territorio nacional (Constitución 1991, art. 24) y que en situación de normalidad, salvo disposición legal, a nadie se le puede impedir su movilización. Sin embargo, no puede perderse de vista que el Gobierno tenía a su disposición herramientas para limitar la movilidad de personas dado el gravísimo contexto de orden público que se presentaba en esa zona. Al decretar el fin de la zona de distención, bien hubiera podido declararse la conmoción interior (Constitución 1991, art. 213) y limitar el derecho a la libre circulación. ${ }^{40} \mathrm{Si}$, tal como lo

40 “Durante el Estado de Conmoción Interior el Gobierno tendrá además la facultad de adoptar las siguientes medidas: a) Restringir, sin que 
expresaban repetidamente los organismos de seguridad y se evidenció con el secuestro, era altamente peligroso el viaje por tierra entre Florencia y San Vicente, ¿por qué no se utilizaron las herramientas legales para impedir el viaje de personas entre estos sitios, aún más de personas con altos niveles de riesgo? Pierde fuerza el argumento de las fuerzas de seguridad ante esta pregunta y refleja que pudo hacerse mucho más para evitar la "autopuesta" en peligro por parte de Betancourt. Es la opinión de este autor que la actuación por parte del Estado fue muy tímida y podría constituir la falla en el servicio por omisión que sustente su responsabilidad en el secuestro, en tanto las autoridades, dentro del marco de la obligación constitucional de velar por sus ciudadanos, no pueden ser unos observadores pasivos que faciliten la violación de los derechos de sus protegidos.

Ahora bien, en cuanto al nexo de causalidad y la posible violación de la posición de garante, el Estado continuamente evadió asumir su obligación de garantizar la seguridad de la candidata, al (en cierta medida) retirarle su escolta, no acompañarla en su viaje, y facilitarle un vehículo para introducirse en la zona de riesgo, o por el contrario, pudo utilizar las herramientas legales para impedir que se expusiera de tal manera al ries-

\footnotetext{
se afecte su núcleo esencial, el derecho de circulación y residencia. En tal virtud podrá limitarse o prohibirse genéricamente la circulación o permanencia de personas o vehículos en horas y lugares determinados que puedan obstruir la acción de la fuerza pública, con miras al restablecimiento del orden público.

En la respectiva entidad territorial podrá también imponerse el toque de queda.

Igualmente podrá exigir a personas determinadas que comuniquen, con una antelación de dos días, todo desplazamiento fuera de la localidad en que tengan su residencia habitual. [...]" (Ley 137 de 1994, art. 38).
}

go. Si bien no existía una obligación de trasladar a Betancourt a San Vicente, se ha debido tomar una de dos posiciones: asumir la seguridad y prestarle los medios para hacer el viaje o utilizar las herramientas legales para impedirlo. Es evidente que, al no hacer ninguna de las dos cosas, el Estado violó su posición de garante y facilitó la violación de los derechos de Betancourt.

A pesar de la dureza de lo anteriormente dicho, no puede perderse de vista la actitud imprudente y negligente de Betancourt, quien con su obstinación respecto a realizar el viaje facilitó enormemente el cometido de las FARC. Cualquier persona sensata, ante las continuas advertencias gubernamentales, hubiese desistido de tal despropósito. Esta actitud de Betancourt sería la carta principal de defensa del Estado, encuadrándose dentro de la excepción de culpa exclusiva de la víctima. Sin embargo, al considerar que el comportamiento de la administración constituyó falla en el servicio y que esta contribuyó a que se produjera el secuestro, la excepción no tendría la entidad para relevar de responsabilidad al Estado. Como se vio en el exp. 17138, la comprobación de este hecho solo permite aminorar el monto de la indemnización.

Analizados todos los elementos, es posible afirmar que el Consejo de Estado hubiese podido condenar a las entidades involucradas, dado que es posible inferir una falla del servicio a partir de los hechos relevantes del caso, así como la violación de la posición de garante, permitiendo de esta forma asignar responsabilidad por los perjuicios derivados del secuestro de Ingrid Betancourt. No sobra recalcar que la evidente negligencia de la exsecuestrada no eliminaría 
la responsabilidad estatal, sino que reduciría la indemnización de los perjuicios.

\section{CONCLUSIÓN}

A lo largo de este texto se ha buscado responder cómo nuestro ordenamiento jurídico, en particular la jurisprudencia contenciosa, analizaría y solucionaría casos donde se imputa responsabilidad al Estado como consecuencia de secuestros cometidos por actores del conflicto armado, es decir, por terceros ajenos a la administración. En este propósito se ha realizado una aproximación jurídica al tema que el encendido debate sobre estas reclamaciones no le permitió realizar a nuestros jueces, y que, en consecuencia, no le ha dejado a las víctimas de secuestro encontrar solución a sus clamores de reparación.

El camino recorrido para llegar a una respuesta ha permitido evidenciar que la jurisprudencia no tiene un conjunto de soluciones particulares para los casos de secuestro, por lo que se hizo necesario acudir a las construcciones generales de aquellos casos donde se imputa responsabilidad al Estado por hechos de actores violentos, independientemente del tipo de delito que haya provocado los daños antijurídicos.

En este marco, el estudio de casos arrojó que la jurisprudencia construye diferentes criterios dependiendo de quién es la víctima, pudiéndose clasificar en tres categorías diferentes. Así, el análisis de los elementos de la responsabilidad estatal varía en función de si la persona es un civil, un militar incorporado voluntariamente a filas o un conscripto. En el primero de los casos, la responsabilidad se construye a título de falla en el servicio de protección, donde la omisión estatal, teniendo en cuenta el contexto de prestación de este servicio, permite asignar responsabilidad partiendo de la base de la ocurrencia de un daño antijurídico y del vínculo entre aquellos, mediante la utilización de la institución de la posición de garante.

En el segundo caso, la estructura resulta ser la misma, siendo relevante añadir que cuando no se evidencia una falla en el servicio o no se comprueba una puesta en riesgo superior al inherente a la profesión militar y policial, no se puede hablar de responsabilidad y siendo los daños son reparados a través de las indemnizaciones a forfait.

Por último, la imputación de responsabilidad cuando la víctima es un conscripto se torna mucho más sencilla que las anteriores, en tanto cualquiera de los tres títulos construidos por la jurisprudencia permiten obtener este resultado. Es importante destacar que en este caso, por lo menos la identificación de un daño especial es posible si se está ante un daño antijurídico, teniendo en cuenta la especial situación en que se encuentran los conscriptos. De esta manera, evidenciado el daño y su antijuridicidad (entendida como el desvalor del rompimiento de las cargas públicas), resta solo evaluar el nexo mediante la posición de garante de la administración respecto a sus soldados.

Estos elementos permitieron analizar y proponer una hipotética solución a los casos planteados de la toma guerrillera a Mitú y el secuestro de la excandidata Betancourt, logrando con 
esto la respuesta a la pregunta de investigación, en el entendido que este tipo de demandas podrían llegar a ser factibles, dependiendo de los hechos de cada caso y lo que se logre probar en cada proceso. Por lo menos respecto a estos dos casos de secuestro (policías y excandidata), es ciertamente probable que la administración hubiese podido ser condenada como responsable. Esto no significa en manera alguna que el Estado colombiano en todos los casos donde se hayan presentado secuestros por actores del conflicto deba responder. Las particularidades de cada caso y su confrontación con las instituciones y criterios encontrados en la jurisprudencia determinarán el éxito de cualquier reclamación que se haga, siendo totalmente factible que en muchos la administración no tenga que ver y no deba ser declarada responsable.

\section{Bibliografía}

\section{Doctrina y literatura}

Betancourt, I. (2010). No hay silencio que no termine. (M. M. Correa \& M. Cardona, Trad.). Bogotá: Aguilar.

Bustamante Ledesma, A. (2003). Responsabilidad extracontractual del Estado. (2da Ed.). Bogotá: Leyer.

GIL Botero, E. (2010). Responsabilidad extracontractual del Estado. (4ta Ed.). Bogotá: Ibáñez.

Henao Pérez, J.C. (1998). El Daño. Análisis comparativo de la responsabilidad extracontractual en derecho colombiano y francés. Bogotá: Universidad Externado de Colombia.
Municipio de Mitú. (s.f). Nuestro municipio. Recuperado 21-abr-2012, de http://www.mituvaupes.gov.co/nuestromunicipio.shtml?apc $=\mathrm{i}-$ $\mathrm{xx}-1-\& \mathrm{~s}=\mathrm{m} \& \mathrm{~m}=\mathrm{I}$

(s.f). Nuestro municipio - Historia. Recuperado 21-abr-2012, de http://www.mitu-vaupes.gov.co/nuestromunicipio.shtml apc $=m I x x-$ $1-\& \mathrm{~m}=\mathrm{f} \#$ historia

(s.f). Nuestro municipio - Vías. Recuperado 21-abr-2012, de http://www.mitu-vaupes. gov.co/nuestromunicipio. shtml?apc $=$ mIxx-1$\& \mathrm{~m}=\mathrm{f \# vias}$

País Libre. (s.f.). Reparación del Estado en casos de secuestro. Recuperado 19-abr2012, de http://www.paislibre.org/alfa/index. php?option=com_content\&view=article\&id=1 239:reparacion-del-estado-en-casos-de-secuest ro\&catid $=9$ : novedades $\&$ Itemid $=31$

PeñA, R.E. (2009). Constitución Política de CoIombia. Bogotá: Ecoe Ediciones.

Ruiz Orejuela, W. (2010). Responsabilidad del Estado y sus regímenes. Bogotá: Ecoe Ediciones.

Tamayo Jaramillo, J. (1996). De la responsabilidad civil. Las presunciones de responsabilidad y sus medios de defensa. (2da Ed.). Bogotá: Temis.

U. de la Sabana. (s.f). Historia del secuestro en CoIombia. Recuperado 1-may-2012, de http:// www.unisabana.edu.co/unidades/adopta-un-secuestrado/secciones/el-secuestro-en-colombia/ historia-del-secuestro-en-colombia/ 


\section{Jurisprudencia}

Autos

Consejo de Estado, S.C.A. Secc. 3ra. Auto 21 febrero 2011, Exp. 39360. C.P. Olga Mélida Valle de La Hoz.

Estudio de casos

Consejo de Estado, S.C.A. Secc. 3ra. Sentencia 25 de febrero de 2009. Exp. 18106. C.P. Ruth Stella Correa.

Sentencia 1 abril 2009. Exp. 16836. C.P. Ruth Stella Correa.

Sentencia 26 enero 2011. Exp. 18617. C.P. SteIla Conto.

Sentencia 25 mayo 2011. Exp. 15838, 18075, 25212. C.P. Jaime Orlando Santofimio.

Sentencia 25 mayo 2011. Exp. 18747. C.P. Jaime Orlando Santofimio.

Sentencia 11 agosto 2011. Exp. 20325. C.P. Mauricio Fajardo.

Sentencia 31 agosto 2011. Exp. 19195. C.P. Jaime Orlando Santofimio.

Sentencia11 noviembre 2011. Exp. 17138. C.P. Myriam Guerrero de Escobar.

\section{Sentencias}

Consejo de Estado, S.C.A. Secc. 3ra. Sentencia del 25 de julio de 2002. Exp. 13744. C.P. María Elena Giraldo.
Sentencia 8 agosto 2002. Exp. 10952 C.P. Ricardo Hoyos.

Sentencia 11 octubre 1990. Exp. 5737. C.P. Gustavo de Greiff.

Sentencia 26 enero 2006.Exp. AG-2001-00213 C.P. Ruth Stella Correa.

Sentencia 4 diciembre 2006. Exp. 13168 C.P. Mauricio Fajardo.

Sentencia 24 marzo 2011. Exp. 19067. C.P. Mauricio Fajardo.

Sentencia26 mayo 2011. Exp. 19977. C.P. Mauricio Fajardo.

Corte Constitucional. Sentencia SU-1184 de 2001. M.P. Eduardo Montealegre.

\section{Prensa}

\section{General}

El EspeCtador. (22 febrero 2012). Ex diputado Sigifredo López demanda al Estado. Recuperado 1 mayo 2012, de http://m.elespectador. com/impreso/sigifredo-lopez/articuloimpreso189264-ex-diputado-sigifredo-lopez-demanda-al-estado

(16 abril 2012).Viuda del mayor Guevara busca conciliación por 923 millones con el Estado. Recuperado 19 abril 2012, de http:// www.elespectador.com/noticias/judicial/articulo-338826-viuda-del-mayor-guevara-buscaconciliar-923-millones-el-estado 


\section{Casos}

Ardila Arrieta, Laura. (31 octubre 2008). Mitú fue el infierno. Recuperado el 21 abril 2012, de http://www.elespectador.com/impreso/nacional/articuloimpreso87232-mitu-fue-el-infierno

América Economía. (9 julio 2010). Estado colombiano niega responsabilidad en el secuestro de Ingrid Betancourt. Recuperado 21 abril 2012, de http://www.americaeconomia.com/ politica-sociedad/politica/estado-colombianoniega-responsabilidad-en-el-secuestro-de-ingrid-betanco

El EspeCtAdor. (1998). Ediciones del 2, 3, 4 y 5 de noviembre.

_ (13 julio 2010). Ingrid Betancourt retira conciliación contra el Estado. Recuperado 21 abril 2012, de http://www.elespectador.com/ noticias/judicial/articulo-213121-ingrid-betancourt-retira-conciliacion-contra-el-estado

EL TIEMPO. (2 noviembre 1998). Las Farc arrasaron Mitú. Recuperado 19 abril 2012, de http://www.eltiempo.com/archivo/documento/ MAM-809458

- (2 noviembre 1998). Sangrientos combates en Mitú. Recuperado 19 abril 2012, de http://www.eltiempo.com/archivo/documento/ MAM-809526

- (2 noviembre 1998). Información es precaria: Serrano. Recuperado 19 abril 2012, de http://www.eltiempo.com/archivo/documento/ MAM-809469
_- (3 noviembre 1998). Incierta situación en Mitú. Recuperado 19 abril 2012, de http:// www.eltiempo.com/archivo/documento/ MAM-831263

__ (3 noviembre 1998). Apoyo aéreo en la selva. Recuperado 19 abril 2012, de http://www.eltiempo.com/archivo/documento/MAM-811736

__ (3 noviembre 1998). En un basurero quedaron 28 cuerpos. Recuperado 19 abril 2012, de http://www.eltiempo.com/archivo/documento/MAM-810407

_- (3 noviembre 1998). Cruel batalla para recuperar Mitú. Recuperado 19 abril 2012, de http://www.eltiempo.com/archivo/documento/ MAM-810636

__ (3 noviembre 1998). Fue imposible contar tantos muertos. Recuperado 19 abril 2012, de http://www.eltiempo.com/archivo/documento/MAM-810439

_- (3 noviembre 1998). La policía de Mitú no conocía la zona. Recuperado 19 abril 2012, de http://www.eltiempo.com/archivo/documento/MAM-811727

_- (4 noviembre 1998). Batalla nocturna para recuperar Mitú. Recuperado 21 abril 2012, de http://www.eltiempo.com/archivo/documento/MAM-846204

- (4 noviembre 1998). Un coronel en poder de las Farc. Recuperado 21 abril 2012, de http://www.eltiempo.com/archivo/documento/ MAM-846350 
_- (4 noviembre 1998). Colombia violó nuestra soberanía: Brasil. Recuperado 21 abril 2012, de http://www.eltiempo.com/archivo/documento/MAM-846201

_- (5 noviembre 1998). Toma y destrucción de Mitú. Recuperado 21 abril 2012, de http://www.eltiempo.com/archivo/documento/ MAM-831091

__ (5 noviembre 1998). Así recuperaron las tropas Mitú. Recuperado 21 abril 2012, de http://www.eltiempo.com/archivo/documento/ MAM-848036

_- (5 noviembre 1998). Por qué Mitú. Recuperado 21 abril 2012, de http://www.eltiempo. com/archivo/documento/MAM-847840

_- (5 noviembre 1998). Rabia y dolor en Mitú. Recuperado 21 abril 2012, de http://www. eltiempo.com/archivo/documento/MAM848407

_- (5 noviembre 1998). Identifican cuerpos de policías. Recuperado 21 abril 2012, de http://www.eltiempo.com/archivo/documento/ MAM-850163

__(24 febrero 2002). Desaparecida, Ingrid Betancourt. Recuperado 22 abril 2012, de http://www.eltiempo.com/archivo/documento/ MAM-1379070

__ (25 febrero 2002).Así fue el secuestro de Ingrid Betancourt. Recuperado 22 abril 2012, de http://www.eltiempo.com/archivo/documento/MAM-1380000
_ (25 febrero 2002). Ingrid: una candidata polémica. Recuperado 22 abril 2012, de http://www.eltiempo.com/archivo/documento/ MAM-1380330

- (25 febrero 2002). El secuestro de Ingrid oscurece la campaña. Recuperado 22 abril 2012, dehttp://www.eltiempo.com/archivo/ documento/MAM-1380318

- (25 febrero 2002). Se enrarece el ambiente electoral. Recuperado 22 abril 2012, de http://www.eltiempo.com/archivo/documento/ MAM-1381544

— (25 febrero 2002). ONU condena el secuestro. Recuperado 22 abril 2012, de http:// www.eltiempo.com/archivo/documento/ MAM-1380324

- (26 febrero 2002). Debate por el secuestro de Ingrid. Recuperado 22 abril 2012, de http://www.eltiempo.com/archivo/documento/ MAM-1382234

- (26 febrero 2002). Atentado contra la democracia. Recuperado 22 abril 2012, de http://www.eltiempo.com/archivo/documento/ MAM-1322488

Revista Semana. (Noviembre 1998). El síndrome de Jacobo. No. 862.

_ (Marzo 2002). Tiempos de guerra. No. 1035.

- (2 julio 2008). ¡Ingrid, los tres americanos y 11 uniformados LIBRES! Recuperado 25 abril 2012, de http://www.semana.com/online/ingrid-tres-americanos-11-uniformadoslibres/113206-3.aspx 